\title{
Biological CONTRIBUtions TO WELl-BEING: The RELATIONSHiPS AMONGST TEMPERAMENT, CHARACTER STRENGTHS AND RESILIENCE
}

\author{
Authors: \\ Ann-Marie K. Hutchinson ${ }^{1}$ \\ Anita D. Stuart ${ }^{1}$ \\ Hester G. Pretorius ${ }^{1}$ \\ Affiliations: \\ ${ }^{1}$ Department of \\ Psychology, University \\ of Johannesburg, \\ South Africa
}

\section{Correspondence to:}

Anita Stuart

email:

anitastuart@global.co.za

\section{Postal address:}

PO Box 312, Featherbrooke

Estate 1746, South Africa

\section{Keywords:}

psychology; personality; psycho-neurobiology; well-being; quantitative; positive psychology

\section{Dates:}

Received: 31 July 2009 Accepted: 10 Feb. 2010

Published: 06 Dec. 2010

How to cite this article: Hutchinson, A.K., Stuart, A.D., \& Pretorius, H.G. (2010). Biological contributions to wellbeing: The relationships amongst temperament, character strengths and resilience. SA Journal of Industrial Psychology/SA Tydskrif vir Bedryfsielkunde, 36(2), Art. \#844, 10 pages, DOI: 10.4102/sajip.v36i2.844

This article is available at: http://www.sajip.co.za

\section{(c) 2010. The Authors.}

Licensee: OpenJournals Publishing. This work is licensed under the Creative Commons Attribution License.

\begin{abstract}
Orientation: Positive psychology emphasises the nurturing of personal strengths, yet little research to date has investigated the role of nature in psychological wellness.

Research purpose: The study aimed to address this dearth by investigating the relationship between temperament, with its biological roots, and psychological well-being and also to ascertain whether character strengths and resilience can be predicted by certain temperament traits.
\end{abstract}

Motivation for the study: Although the biological bases of mental illness have been researched extensively in past studies, there is very little research regarding the biological bases of psychological wellness.

Research design, approach and method: This quantitative study selected a sample of 620 participants and applied four measuring instruments, namely the Zuckerman-Kuhlman Personality Questionnaire, the Values in Action - Inventory of Strengths (VIA-IS) , the Sense of Coherence scale and the Resilience scale to measure temperament and well-being. Correlations and logistic regression analyses were used to analyse the data.

Main findings: There are relationships between certain biologically based temperament traits and the psychological constructs of character strengths and resilience. Logistic regression models, using temperament as the independent variable, correctly predicted high and low scores on the Sense of Coherence scale, the Resilience scale and the (VIA-IS) with $64 \%-76.1 \%$ accuracy.

Pratical/managerial implications: Understanding the physiological substrates of flourishing and being able to predict strengths based on temperament promise advances in applying positive psychology concepts.

Contribution/value-add: Values, ethics, character strengths, virtues and resilience are universal and may be entrenched in biology, according to some theorists. This has not been researched much, however. The current study addressed this dearth.

\section{INTRODUCTION}

\section{Paradigmatic orientation of study: Positive psychology}

While historically psychology has typically focused on identifying and treating mental illness and psychological deficits, a number of psychologists and researchers have initiated a paradigm shift to one of positive psychology, which emphasises developing and maintaining well-being and personal strengths. Positive psychology should be viewed as a framework complementary to the deficit-based medical model.

Seligman $(2002,2003)$ indicates that although psychology originated as an approach to identify genius and nurture talents prior to World War II, in the aftermath of the war psychology became a science devoted to identifying and treating mental illness utilising the disease model. Strümpfer (2006) points out that many developments that were not necessarily purely focused on pathology were taking place in the field of psychology at the time although the general emphasis in psychology was on psychopathology. Many theorists and psychologists operating from this problem-orientated framework have begun to question the usefulness of such a paradigm.

The strengths perspectiveencapsulates 'assumptions and attributions abouthealth, motivation, capacities, potential and social functioning' (Strümpfer, 2006, p. 12). Martin Seligman (2002) is considered to be the founding father of the field of positive psychology and is often credited with coining the term positive psychology (Strümpfer, 2006). However, Abraham Maslow already used the phrase 'positive psychology' in 1954 (Maslow, 1954, p. 353), while Seligman only began using the term positive psychology in 1997 (Strümpfer, 2006). It should thus be noted that positive psychology, rather than being a new paradigm, is a return to some of the ideas of earlier psychologists who have encouraged focusing on human strengths. For example, many theorists proposing positive psychology concepts, such as Anthony and Cohler (1987), Bohart and Greening (2001), McLafferty and Kirylo (2001), Murphy and Moriarty (1976), Ryff and Keyes, (1995), Snyder and Lopez (2002), Strümpfer (1990, 1995), Werner and Smith (1982) and Wissing and Van Eeden (2002), did so long before Seligman's (2002) emphasis on creating a 'paradigm shift' to positive psychology. The current movement in positive psychology therefore can be viewed as a return to this focus on human strengths and potentialities as originally proposed by Maslow and the humanistic psychology movement.

\section{Key focus of the study}

\section{Biological concomitants of well-being}

Seligman (2002) states that character strengths are consistent traits that can be nurtured and developed. This statement refers to the nature versus nurture debate, which has played a great role in psychological 
literature in the past. Although modern psychologists and researchers tend to agree that both nature and nurture play a role in the development of individuals, most research (see, for example, a collection of studies by various researchers compiled by Strelau, Farley and Gale [1986] and a compilation of studies by Bates and Wachs [1994]) has focused on the role of nature and nurture in mental illness. The focus in research thus far has not been to investigate the interface of nature versus nurture in psychological wellness. The study of epigenetics in particular has brought new developments regarding the biological genetic basis of some mental illnesses. Although this greatly contributes to knowledge regarding identifying and treating mental illness, it does not give an indication as to whether biology plays a role in the development of psychological wellness. The current research addresses this dearth in the literature.

\section{Trends from the research literature}

The main constructs of the study are temperament and wellbeing, which will be explicated, followed by indications of the possible interface of these constructs, which gave rise to the central hypotheses of the study.

\section{Temperament}

One construct in psychology that focuses on the biological basis of behaviour is temperament. Temperament is defined as stable and enduring, impacting the thoughts, feelings and behaviours of an individual that appear in the formative years of life (Buss \& Plomin, 1984). Although many theories of temperament with strong biological links can be found in the literature, for example the Pavlovian and the Strelau theories of temperament, the focus of the current research is on the Western approach to temperament. Various theories that offer insight into temperament from a biological perspective, including Eysenck's theory of temperament and Gray's neuropsychological model of temperament, serve the purpose of demonstrating the link between biology and behaviour and lay the foundations for the Zuckerman-Kuhlman theory of temperament, which is central to the current study.

Based on much research that demonstrates the link between neurobiological systems and temperament, Zuckerman formulated his theory of five behavioural traits namely impulsive sensation seeking, neuroticism-anxiety, aggression-hostility, activity and sociability (Zuckerman, 1991). An example of such research is the work by Gibson and Cook (1996) that links neuroticism to inherited emotional lability of the autonomic nervous system. Further examples are research by Davidson, Jackson and Kalin (2000) and Tomarken, Davidson and Henriques (1990) who linked activation of the right frontal lobe to negative affect such as depression and anxiety, inhibition and avoidance behaviour whereas activation of the left frontal lobe facilitates positive emotionality such as happiness, joyfulness and approach behaviour; research by Daderman, Meurling and Hallman (2001), Wills, Sandy, Yaeger and Shinar (2001) and Zuckerman, Buchsbaum and Murphy (1980) who showed that sensation seeking, extraversion and impulsivity can be linked to low levels of monoamine oxidase (MAO) in the blood platelets; and research by Zuckerman (1991) who showed that hormonal factors may affect aggression and hostility as well as general levels of activity. Zuckerman's (1991) five factors have been referred to as 'The Alternative Five' to distinguish them from 'The Big Five' personality factors (Costa \& McCrae, 2001) and describe individual differences in behaviour in a stressful situation (Vollrath, 2001).

Strelau (1998) noted that although temperament is biologically based, there is an interactional effect among temperament, personality and the environment. Thishighlights that individual behaviour is not deterministic and can be influenced by the environment (Oniszczenko et al., 2003). Similarly, behavioural geneticists suggest that both genes and environment affect behaviour, emphasising the role of genotype or genetic makeup as well as environment and phenotype on measurable behaviours (Carey, 2003; DiLalla, 2004).

\section{Psychological well-being}

There are a number of theories that focus on psychological well-being. Due to renewed interest in 'positive psychology' and the constructs of psychological strengths, salutogenesis and resilience, these constructs were chosen to represent wellbeing in the current study. The literature on character strengths will be explored first, followed by a discussion of salutogenesis and resilience.

For many years the topic of character, values, ethics and virtues has not received much attention in the field of psychology as many psychologists were resistant to the idea that values could infiltrate the science of objective research (McCullough \& Snyder, 2000). Allport, the well-known personality trait theorist of the 20th century, argued that the study of character belonged in the field of philosophy and banned the term character from academic discourse on personality (Allport \& Vernon, 1930; Nicholson, 1998). Traits, however, were considered to be objective qualities without any moral significance. This argument was in line with the largely positivistic spirit in social science that distinguished rigidly between fact and value (Peterson \& Seligman, 2004).

A survey by Public Agenda in 1999 in the United States of America revealed that the public believe that not learning values is one of the biggest problems facing people today, even more so than drugs or violence (Peterson \& Seligman 2004). Peterson and Seligman argue that virtues are universal and that they may in fact be entrenched in biology, but they have not to date investigated this line of thinking. Also, they suggest that it is possible that evolution has led to the selection of certain virtues necessary for solving certain issues essential for the survival of the species. Current research indicates that character strengths can be developed and taught but what is lacking in the field are the conceptual and empirical tools that are needed for designing and evaluating interventions (Park, 2004).

A valuable contribution to the field of positive psychology is the attempt by Peterson and Seligman (2004) to operationalise human strengths and virtues by creating a classification system on the same principles as the Diagnostic and Statistical Manual IV (DSM-IV) for mental illness, referred to as the 'un-DSM' for measuring psychological wellness. This classification system is known as the Values in Action - Inventory of Strengths or the VIA-IS (Peterson \& Seligman, 2004). The classification comprises 24 character strengths, which may further be categorised into six broad virtues, namely wisdom and knowledge, courage, humanity, justice, temperance and transcendence. Strümpfer (2006) acknowledges that there may be value in the development of the VIA-IS (Peterson \& Seligman, 2004) insofar as it represents a mental health manual complementary to the DSM-IV. It has been argued that the VIA-IS can be used across time and cultures. However, very few studies as yet have been conducted in South Africa to confirm that this is indeed the case in what is arguably a very particular and unique context. One of the aims of the current study is to address this question by investigating the usefulness of the VIA-IS in respect of a South African sample.

With the DSM-IV of the American Psychiatric Association (1994) it is possible to measure what goes wrong with people, but the VIA-IS classification of character strengths attempts to measure what is right. This assists in advancing psychological well-being and mental health way beyond the absence of disease, distress and disorder.

Apart from the theory on character strengths and virtues, another theory that focuses on well-being by highlighting an individual's resilience is salutogenesis. Aaron Antonovsky (1987) is well known for his work in this area, especially his focus on what is known as sense of coherence. While the pathogenic paradigm focuses on why and how illness 
occurs, the salutogenic paradigm focuses on the origins and development of health and wellness. Sense of coherence is a global orientation that consists of three aspects, namely comprehensibility, manageability and meaningfulness, and can be measured with the Sense of Coherence scale (Antonovsky, 1987). This theory contends that some people are more resilient and have higher levels of well-being than others. For example, although a number of people may experience a similar event (such as an earthquake), everyone's psychological responses will differ; some will develop healthy outcomes while others will develop pathology.

Wagnild and Young's (1993) work on resilience also represents a focus on well-being as opposed to pathogenesis. Resilience refers to the ability to adapt and be successful under difficult or challenging circumstances (Tusaie \& Dyer, 2004). The Resilience scale (Wagnild \& Young, 1993) measures the extent to which an individual perceives him- or herself as being resilient and able to cope with difficulties and challenges in life. Although there are many scales that have been developed to measure resilience, this particular instrument was deemed to be the most appropriate for the current study as it is positively phrased and thus complements the salutogenic focus of the Sense of Coherence scale (Antonovsky, 1987). Although some research has been conducted on the personality variables associated with salutogenesis, very little research has explored the strengths of individuals in terms of their relationship to resilience.

\section{Interface between temperament and well-being: Central hypotheses}

Research indicates possible links between temperament and pathology, thus implicating a biological basis for certain pathologies. Slessareva and Muraven (2004) and Strelau (1998), for example, have found that anxiety is associated with the temperament trait of sensitivity, with higher levels of sensitivity being associated with heightened anxiety levels. Furthermore, neuroticism predisposes individuals to interpreting events more negatively (Magnus, Diener, Fujita, \& Pavot, 1993). Boddeker and Stemmler (2000) found that individuals who score high on neuroticism tend to react with strong physiological and behavioural anger, indicating a link between neuroticism-anxiety and aggression-hostility. Also, the traits of neuroticism and anxiety have been found to correlate negatively with sociability (Zuckerman, 1991). The literature furthermore suggests that neuroticism-anxiety and aggression-hostility contribute to a low sense of coherence (Van Zyl, 2007).

Despitemanyindications of a relationshipbetween temperament and pathology, few research studies have investigated the possible links between temperament and well-being, in other words the possible biological basis for psychological strengths and resilience. It is possible that low levels of sensitivity are associated with low anxiety levels and possibly also with high levels of the virtues of character strengths. It furthermore seems likely that low levels of neuroticism-anxiety may predispose individuals to experiencing life events more positively.

Some research indicates possible links between character strengths and resilience, by inference more that by objective research. It is possible that resilient individuals, as described by Geyer (1997) and Keyes and Haidt (2003), may be more likely to utilise creative problem-solving strategies and are more curious and open-minded, in this way displaying the virtue of wisdom and knowledge. Antonovsky (1987) claims that individuals with a high sense of coherence, who are also therefore resilient, view demanding and stressful life situations as challenges worthy of engagement, thus possibly displaying the virtue of courage. The virtue of humanity refers to the character strengths of love, kindness and social intelligence. Strümpfer (1990) noted that various generalised resistance resources or GRRs facilitate resilience, emphasising the interpersonal or relational GRRs. It thus seems likely that the positive aspects of relationships may facilitate resilience. The character strengths that constitute the virtue of justice are citizenship, fairness and leadership. Again, these factors may contribute to GRRs, which in turn may play an important role in facilitating resilience (Antonovsky, 1987; Long, 2001; Strümpfer, 1990). Temperance consists of the character strengths of forgiveness and mercy, humility and modesty. Resilient individuals are likely to avoid being vengeful (Peterson \& Seligman, 2004). The virtue of transcendence includes appreciation of beauty and excellence, gratitude, hope, humour and spirituality. Research has indicated that high levels of gratitude increase psychological well-being (Emmons \& McCullough, 2003; Peterson \& Seligman, 2004; Seligman, Steen, Park \& Peterson, 2005). Calicchia and Graham (2006) found that those individuals with high resilience levels portray coherent beliefs about the higher purpose and meaning of the universe and beliefs about the meaning of life that shape conduct.

\section{Central research hypothesis 1}

Against the background of the literature discussed above regarding indications of relationships between temperament and psychopathology and thus possibly between temperament and well-being, and inferences of relationships between character strengths and resilience, the first central research (alternative) hypothesis of this study posited that there are statistically significant relationships among temperament, character strengths and resilience, as measured by the Zuckerman-Kuhlman Personality Questionnaire (Zuckerman, Kuhlman, Teta, Joireman, \& Kraft, 1993), the VIA-IS (Peterson \& Seligman, 2004), the Sense of Coherence scale (Antonovsky, 1987) and the Resilience scale (Wagnild \& Young, 1993), respectively.

\section{Central research hypothesis 2}

The possible relationships among temperament, character strengths and resilience have been explicated above, mostly based on studies of psychopathology. In no previous studies, however, have regression models been used in order to explore these relationships, and the question remains whether temperament can also predict well-being, in the form of character strengths and resilience in healthy individuals. Similarly, no logistic regression models have been utilised to this end. There is also little research available from which one can infer possible causal relationships among these constructs. The second central research hypothesis posited that temperament traits as measured by the Zuckerman-Kuhlman Personality Questionnaire (Zuckerman et al., 1993) will predict high or low scores on the VIA-IS (Peterson \& Seligman, 2004), the Sense of Coherence scale (Antonovsky, 1987) and the Resilience scale (Wagnild \& Young, 1993), respectively. Investigating the possibility of predicting psychological well-being in this way was a principle objective of this study.

\section{Research objectives}

Based on the above brief exploration of the 'new' focus on psychological wellness, the indicated dearth of research regarding temperament and the biological bases of well-being, and the lack of research addressing the possible relationships between character strengths and resilience, the first research objective of this study was to assess the extent to which there are relationships among temperament, character strengths and resilience, both in terms of the subdimensions and the constructs as a whole. The following specific research questions were formulated in this regard:

- Are there statistically significant correlations between the Zuckerman-Kuhlman Personality Questionnaire (Zuckerman et al., 1993) and the VIA-IS (Peterson \& Seligman, 2004)?

- Are there statistically significant correlations between the Zuckerman-Kuhlman Personality Questionnaire and the Sense of Coherence (Antonovsky, 1987) and Resilience (Wagnild \& Young, 1993) scales? 
- Are there statistically significant correlations between the VIA-IS (Peterson \& Seligman, 2004) and the Sense of Coherence (Antonovsky, 1987) and Resilience (Wagnild \& Young, 1993) scales?

A second objective was to investigate whether the biological construct of temperament predicts character strengths and resilience in the late adolescence-young adulthood life phase. The following specific research questions were formulated in this regard:

Can temperament as measured by the Zuckerman-Kuhlman Personality Questionnaire (Zuckerman et al., 1993) predict:

- $\quad$ sense of coherence as measured by high or low scores on the Sense of Coherence scale (Antonovsky, 1987)

- resilience as measured by high or low scores on the Resilience scale (Wagnild \& Young, 1993)

- wisdom and knowledge as measured by high or low scores on the wisdom and knowledge subscale of the VIA-IS (Peterson \& Seligman, 2004)

- courage as measured by high or low scores on the courage subscale of the VIA-IS (Peterson \& Seligman, 2004)

- humanity as measured by high or low scores on the humanity subscale of the VIA-IS (Peterson \& Seligman, 2004)

- justice as measured by high or low scores on the justice subscale of the VIA-IS (Peterson \& Seligman, 2004)

- temperance as measured by high or low scores on the temperance subscale of the VIA-IS (Peterson \& Seligman, 2004)

- transcendence as measured by high or low scores on the transcendence subscale of the VIA-IS (Peterson \& Seligman, 2004)?

\section{Potential value of study}

An understanding of the physiological substrates of flourishing and the possibility of predicting character strengths, values, virtues and resilience based on certain temperament traits holds promise for the application of positive psychology concepts aimed at promoting psychological well-being. Equipping individuals with an understanding of their natural affinity for psychological well-being, as implied by their temperament, empowers those individuals to explore and develop their unique character strengths and to identify whether or not they would need to actively engage in developing their own resilience. Preventative intervention strategies including wellnessenhancing programmes may be developed for individuals in various contexts such as career guidance, psychological counselling, workshops and training courses. Importantly, investigating temperament, character strengths and resilience in young adults may result in specific intervention strategies aimed at assisting young people in managing the turbulence and transitional nature of this life stage (Santrock, 2003).

\section{Delineation of empirical investigation}

After a brief description of the research design, the research methods employed to attain the objectives of the study will be explicated, including a description of the research participants, the measuring instruments, the procedure followed and the statistical methods employed to analyse the data. The article will end with a discussion of the results and a conclusion.

\section{RESEARCH DESIGN}

\section{Research approach}

The research objectives and stated hypotheses call for a positivistic research approach. A large sample of young adults was selected and a quantitative ex post facto design was used. The reliabilities of the various measuring instruments were ascertained and factor analysis was used to assess the applicability of the VIA-IS (Peterson \& Seligman, 2004) for a South African sample. The normality of distribution of the data was calculated. Thereafter, correlation techniques and logistic regressions were employed to analyse the data.

\section{Research method \\ Research participants}

A convenience sample of male and female young adults $(N=$ 620) was selected from a tertiary institution and the private sector. Certain biographical information was requested from the participants in order to investigate the limitations of the sample. Individuals were asked to disclose their age, gender and home language. The participants' ages ranged from 17 to 30 years, with a fairly balanced male-female ratio of $42: 58 \%$. The language distribution of valid and relevant responses was as follows: African $36.7 \%$ and European $63.3 \%$. Other languages that individually did not constitute a significant proportion of the data amounted to $6.5 \%$ of the sample. The participants all met the requirements for admission to a tertiary institution or successfully functioned in the private sector and thus were assumed to be linguistically competent to complete the questionnaires in English. In order to ensure that all the English words were understood, the researcher or an assistant was always available to answer questions and explain concepts. All participants were considered to be young adults exploring life roles, becoming independent and experiencing a transitional life phase. Therefore all participants were deemed to meet the criterion of having experienced stressors and consequently the opportunity to demonstrate resilience and different character strengths.

\section{Measuring instruments}

Four questionnaires were used, all of which are self-report measures.

Zuckerman-Kuhlman Personality Questionnaire (Zuckerman et al., 1993): The Zuckerman-Kuhlman Personality Questionnaire is a 99-item paper-and-pencil test consisting of true or false questions. It consists of five subscales. The questionnaire takes 15 to 20 minutes to complete. Scores are added together for each subscale. This questionnaire was included in the test battery due to the strong biologically based theory underlying the temperament dimensions and to determine whether there were any differences among the participants with regard to their temperament.

The impulsive sensation-seeking subscale, consisting of 19 items, indicates the level to which an individual is unable to plan effectively or is prone to acting impulsively without thinking, as well as the eagerness of an individual to engage in certain risks for excitement (Vollrath, 2001; Zuckerman et al., 1993). The neuroticism-anxiety subscale, with its 19 items, describes states of emotional distress, feelings of tension, obsessive indecision and sensitivity to critique. Aggression-hostility is a subscale made up of 17 items and measures the probability that an individual may demonstrate verbal aggression, rudeness and vengefulness (Vollrath, 2001). The activity subscale, consisting of 17 items, measures an individual's inability to relax and indicates rather a need to be continuously active. It indicates the need for a challenging, busy lifestyle and high energy levels (Zuckerman, 2002). Sociability is a 17-item subscale and indicates the leve of social behaviour of an individual (Zuckerman, 2002). Social desirability is controlled for by utilising 10 such items.

The scale has acceptable reliability. Internal reliabilities for the subscales, test-retest reliabilities and Cronbach Alpha coefficients vary between 0.73 and 0.86 (Aluja, Garcia \& Garcia, 2002; Zuckerman, 2002; Zuckerman, et al., 1993). Zuckerman (2002) investigated the convergent and discriminant validity of the Zuckerman-Kuhlman Personality Questionnaire with the NEO-PI-R (Costa \& McCrae, 2001) and Eysenck Personality Questionnaire (Eysenck \& Eysenck, 1985) by computing intercorrelations. The results indicate a high level of convergence among factors as represented by the scales from the three psychometric tests. 
VIA-IS (Peterson \& Seligman, 2004): The VIA-IS was developed as a 'manual of the sanities' based on the same principles as the DSM-IV. It consists of 240 items and is a self-report questionnaire scored on a five-point Likert scale. The items measure 24 character strengths that are further categorised into six virtues. The six virtues were used for the purpose of analysis in this study. Responses are scored manually with high scores in a particular category indicating a high level of this strength in the participant. The questionnaire takes between 20 and 30 minutes to complete. For the purposes of this study, permission to use the instrument and scoring criteria were obtained after a telephonic discussion regarding the present study with Deb Pinger, Executive Director of the VIA Institute on Character, who approved the use of the VIAIS (Peterson \& Seligman, 2004) for the present study. This questionnaire is relatively new and reliability and validity tests thus far have been mostly by the authors themselves.

In a pilot study in the USA $(N=250)$, Peterson and Seligman (2004) found internal consistency Alphas of $>0.70$ for all scales and further research by the authors support these findings. They report further that test-retest correlations for all scales are $>0.70$. The authors also suggest that the questionnaire is reliable and valid across demographic groupings, with the exception of higher scores on the spirituality subscale for African Americans. The VIA-IS (Peterson \& Seligman, 2004) was originally designed for the USA and English-speaking countries with cross-cultural comparisons completed in various non-English-speaking countries such as Asia, Africa, the Middle East and Continental Europe.

Sense of Coherence scale (Antonovsky, 1987): The Sense of Coherence scale consists of three subscales namely comprehensibility, manageability and meaningfulness, but Antonovsky (1987) suggests focusing on sense of coherence as a whole and not on the scores of the subscales as he deems this to be more theoretically sound. Antonovsky (1987) conceptualised the comprehensibility scale as a measure of the extent to which an individual can understand life events and situations as clear, ordered and consequential. The second subscale, manageability, is defined as the measure of control that an individual exhibits in different situations. The meaningfulness scale measures the extent to which a person feels that events make sense to him or her in an emotional way (Antonovsky, 1987). The Sense of Coherence scale (Antonovsky, 1987) is a 29item semantic-differential questionnaire, and the development was based on Guttman's phase theory (Antonovsky, 1993). Semantic differential scales are characterised by a seven-point continuum, anchored by contrasting descriptions on each side (Dawis, 1998). The 13-item version of the Sense of Coherence scale (Antonovsky, 1987) has been found to be less reliable due to the unreliability of the subscales (Hart, Hittner \& Paras, 1991). Cloete (2003) also reports that the full scale is more reliable than the 13-item scale, and thus in this study, it was decided that the full scale should be used. The full 29-item scale takes 15 to 20 minutes to complete. Thirteen of the total of 29 items are formulated negatively and these items must therefore be scored in reverse.

The Cronbach Alpha reliability coefficients range from 0.82 to 0.95 (Erikkson \& Lindstrom, 2005) and Antonovsky (1987) found values from 0.84 to 0.93 , which is indicative of internal consistency and reliability. A high score represents a strong sense of coherence. In a study by Erikkson and Lindstrom (2005), the validity and reliability of the Sense of Coherence scale (Antonovsky, 1987) were systematically investigated. The researchers concluded that the scale seems to be a reliable, valid and cross-culturally applicable scale (Erikkson \& Lindstrom, 2005).

Resilience scale (Wagnild \& Young, 1993): The Resilience scale (Wagnild \& Young, 1993) measures the extent to which an individual perceives him- or herself as being resilient and able to cope with difficulties and challenges in life. Although there are many scales that have been developed to measure resilience, this particular instrument was deemed to be the most appropriate for the current study as it is positively phrased and thus complements the salutogenic focus of the Sense of Coherence scale (Antonovsky, 1987). The Resilience scale (Wagnild \& Young, 1993) is a 26-item positively worded self-report questionnaire that defines resilience as a positive personality characteristic that enhances adaptation. Respondents select answers on the answer sheet according to a seven-point Likert scale, with higher scores indicating higher resilience.

An Alpha coefficient of 0.91 obtained indicates good reliability for the Resilience scale (Wagnild \& Young, 1993) with inter-item correlations of between 0.50 and $0.70(p<0.001)$. Content validity is reported to be good based on generally accepted definitions of resilience from the authors and individuals deemed to demonstrate resilience as well as an expert panel (Ahern, Kiehl, Sole, \& Byers, 2006). Concurrent validity was indicated by high correlations between the Resilience scale (Wagnild \& Young, 1993) and other well-established valid measures of constructs linked to resilience and outcomes of resilience, such as depression $(r=-0.37)$, life satisfaction $(r=0.30)$, morale $(r=$ $0.28)$ and health $(r=-0.26)$.

All of the abovementioned measuring instruments have been used in previous research and were deemed culturally fair. The Sense of Coherence scale (Antonovsky, 1987) is published in English but is also available in Afrikaans and Tswana. However, this questionnaire was presented in English since all the participants were fluent in English, and since the ZuckermanKuhlman Personality Questionnaire (Zuckerman et al., 1993), VIA-IS (Peterson \& Seligman, 2004) and Resilience scale (Wagnild \& Young, 1993) are only available in English.

\section{Research procedure}

Permission to conduct the study was requested from a tertiary institution and from individuals in the private sector. The researcher presented a short five-minute information session on the aims of the study and other issues, such as informed consent, but potential participants were not given any directives that might jeopardise the results of the research. Participants were assured of anonymity and confidentiality and were instructed not to put their identifying information on the questionnaires. The researcher gave verbal instructions at every session and instructions for the various questionnaires were also printed on the questionnaire. The researcher was present at each of the testing sessions. Participants were encouraged to answer as quickly as possible, as per instructions in the individual questionnaires, and were informed that the first answer that comes to mind is usually the most accurate one. The raw data were submitted to a statistical consulting service in electronic format for statistical analysis.

\section{Statistical analyses}

Various statistical analyses were conducted on the raw data collected from the questionnaires. The reliabilities of the various measuring instruments were established by means of the Cronbach Alpha test. Statistical techniques were utilised to evaluate the normality of the distribution of the data. Pearson's product moment correlations were used to assess the potential relationships among the variables. Thereafter canonical correlations were performed in order to establish the extent of any potential relationship among the constructs. Lastly, logistic regression was performed to determine whether the biologically-based construct of temperament could predict high versus low scores on the tests of character strengths and resilience in individuals.

\section{RESULTS}

A widely used measure of reliability is Cronbach's Alpha (Neuman, 2003). In general an Alpha coefficient greater than 0.7 indicates that the test exhibits internal reliability. The 


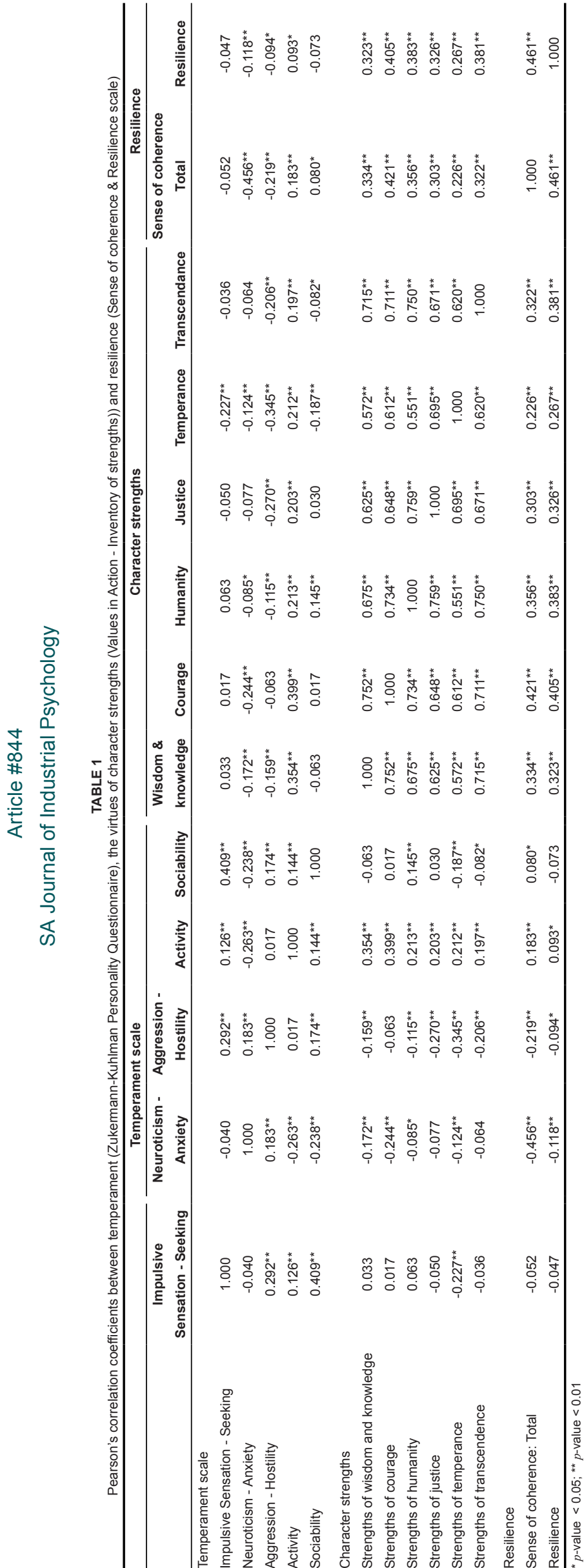

various subscales of the Zuckerman-Kuhlman Personality Questionnaire (Zuckerman et al., 1993) as well as the various character strengths comprising the VIA-IS (Peterson \& Seligman, 2004) all exhibited good reliabilities, with Alpha coefficients of between 0.728 and 0.834 . The subscales of the Sense of Coherence scale (Antonovsky, 1987) did not all exhibit high reliability, but the scale as a whole did (Alpha $=0.831$ ). Sense of coherence was therefore used as a single measure. This is supported by Antonovsky (1987), who suggests the use of the sense of coherence construct as a single measure. The Resilience scale (Wagnild \& Young, 1993) exhibited very high reliability, with an Alpha of 0.940 .

Inspection of the skewness and kurtosis of the distributions of the various scales and subscales did not seem to indicate non-normality; however, formalised tests of normality (i.e. the Kolmogorov-Smirnov test and the Shapiro-Wilk's test) indicated non-normal distributions for all subscales of the ZuckermanKuhlman Personality Questionnaire (Zuckerman, et al., 1993), some virtues of character strengths as measured by the VIA-IS (Peterson \& Seligman, 2004) and both the Sense of Coherence scale (Antonovsky, 1987) and the Resilience scale (Wagnild \& Young, 1993) at the 5\% level. Logistic regression analyses were therefore utilised, since this type of analysis does not require independent variables to be normally distributed.

Pearson's product moment correlations indicating relationships among variables are depicted in Table 1.

From Table 1 it can be seen that resilience, represented by both the Sense of Coherence (Antonovsky, 1987) and Resilience (Wagnild \& Young, 1993) scales, exhibits statistically significant correlations with the neuroticism-anxiety, aggression-hostility and activity subscales of temperament on the ZuckermanKuhlman Personality Questionnaire (Zuckerman et al., 1993). Furthermore, the sense of coherence construct is statistically correlated with the sociability subscale of temperament. Many of the virtue categories of character strengths displayed statistically significant correlations with the various subscales of temperament. All the subscales of temperament correlated significantly with temperance. The impulsive sensationseeking subscale of temperament was not associated with any virtues of character strengths other than temperance. Neuroticism-anxiety was correlated with all virtues other than that of justice, while aggression-hostility was correlated with all virtues except courage. The activity subscale of temperament exhibited statistically significant correlations across all virtues of character strengths. The sociability subscale showed correlations with humanity, temperance and transcendence.

Whereas the standard Pearson product moment correlation coefficient measures the relationships between two variables, canonical correlations involve forming linear combinations of variables and investigating the relationship among these sets of variables. It is regarded as a particularly powerful technique in situations where multiple dependent and independent variables are used.

A canonical correlation of 0.533 was found between the temperament scale and the virtues of character strengths scale. The canonical correlation between resilience and the virtues of character strengths was 0.505 and that between temperament and resilience was 0.493 . All these canonical correlations are statistically significant. These results are depicted in Table 2 below:

Null hypothesis 1 is thus rejected and the stated alternative hypothesis accepted, namely that there are statistically significant relationships among the subscales of the various measuring instruments as well as among the sets of variables comprising the instruments.

Logistic regression can be used for predictive purposes where the data distributions are non-normal. Given that the 
TABLE 2

Canonical Correlations and test for remaining correlations

\begin{tabular}{llllll}
\hline Constructs & Correlation & Wilk's Lambda & Chi-sqaure & $d f$ & Sig. \\
\hline Temperament and character strengths & 0.533 & 0.476 & 454.386 & 30 & $0.000^{\star *}$ \\
Resilience and character strengths & 0.493 & 0.742 & 182.047 & 10 & $0.000^{\star *}$ \\
Temperament and resilience & 0.505 & 0.735 & 187.439 & 12 \\
\hline
\end{tabular}

TABLE 3

Logistic regression classification and output

\begin{tabular}{|c|c|c|c|c|}
\hline & & \multicolumn{2}{|c|}{ Predicted values } & \multirow{2}{*}{$\begin{array}{c}\% \\
\text { Correct }\end{array}$} \\
\hline & & Low & High & \\
\hline \multirow[t]{2}{*}{ Observed sense of coherence } & Low sense of coherence & 116 & 37 & 75.8 \\
\hline & High sense of coherence & 36 & 116 & 76.3 \\
\hline Overall percentage & & - & - & 76.1 \\
\hline \multirow[t]{2}{*}{ Observed Resilience scale score } & Low Resilience sale score & 91 & 52 & 63.6 \\
\hline & High Resilience scale score & 46 & 112 & 70.9 \\
\hline Overall percentage & & - & - & 67.4 \\
\hline \multirow[t]{2}{*}{ Observed wisdom and knowledge } & Low wisdom and knowledge & 110 & 42 & 72.4 \\
\hline & High wisdom and knowledge & 42 & 110 & 72.4 \\
\hline Overall percentage & & - & - & 72.4 \\
\hline \multirow[t]{2}{*}{ Observed courage } & Low courage & 121 & 38 & 76.1 \\
\hline & High courage & 35 & 114 & 76.5 \\
\hline Overall percentage & & - & - & 76.3 \\
\hline \multirow[t]{2}{*}{ Observed humanity } & Low humanity & 121 & 44 & 73.3 \\
\hline & High humanity & 53 & 101 & 65.6 \\
\hline Overall percentage & & - & - & 69.6 \\
\hline \multirow[t]{2}{*}{ Observed justice } & Low justice & 109 & 46 & 70.3 \\
\hline & High justice & 56 & 89 & 61.4 \\
\hline Overall percentage & & - & - & 66.0 \\
\hline \multirow[t]{2}{*}{ Observed temperance } & Low temperance & 125 & 34 & 78.6 \\
\hline & High temperance & 41 & 101 & 71.1 \\
\hline Overall percentage & - & - & - & 75.1 \\
\hline \multirow[t]{2}{*}{ Observed transcendence } & Low transcendence & 108 & 43 & 71.5 \\
\hline & High transcendence & 59 & 78 & 56.9 \\
\hline Overall percentage & - & - & - & 64.6 \\
\hline
\end{tabular}

assumption of normality was rejected by the formalised tests of normality, it was decided to use logistic regression. Logistic regression requires binary dependent variables, and as such the dependent variable was dichotomised for each model. Different models were fitted for temperament and sense of coherence, temperament and resilience, and temperament and character strengths. In all three models the dependent variable was dichotomised by excluding the interquartile range.

A classification table indicates the predictive accuracy of the models fitted. The classification table for the current study is depicted in Table 3.

As can be seen from Table 3, the logistic regression models using the neuroticism-anxiety, aggression-hostility and activity subscales of temperament as the independent variables were able to correctly predict high and low scores on the Sense of Coherence scale with $76.1 \%$ accuracy. The neuroticism-anxiety, aggression-hostility, activity and sociability subscales of temperament were able to correctly predict high and low scores on the Resilience scale with $67.4 \%$ accuracy. Regarding the virtues associated with character strengths, the temperament subscales of aggression-hostility and activity were the strongest predictors in the logistic regression models, predicting high and low scores of wisdom and knowledge with $72.4 \%$ accuracy, courage with $76.3 \%$ accuracy, humanity with $69.6 \%$ accuracy, justice with $66 \%$ accuracy, temperance with $75.1 \%$ accuracy and transcendence with $64.6 \%$ accuracy.

The results of the logistic regression models provide support for the second postulate, and thus null hypothesis 2 is rejected. The results indicate that well-being can be predicted with statistical significance by certain temperament traits.

\section{DISCUSSION}

\section{Relationships among the three main constructs}

The research was executed against the backdrop of positive psychology, and the first main objective of the study was to ascertain whether there are statistically significant relationships between the biologically based measure of temperament and the two measures of well-being, namely sense of coherence and resilience.

The results indicate that there are indeed relationships among temperament, character strengths and resilience, both in terms of the subscales of the measuring instruments and the constructs as a whole.

One of the more significant correlations identified in the present study is that between the activity subscale of temperament and the virtues of character strengths. Activity displayed positive, statistically significant correlations with all virtues. This suggests that a proactive lifestyle and high energy levels may be associated with the development of all character strengths.

During young adulthood individuals may be faced with difficult decisions and a general sense of change and turbulence, but enhancing personal character strengths and resilience may assist young people in sustaining psychological health and well-being. The findings of the current study are in line with the literature, which suggests that although temperament is biologically based, there is an interactional effect among temperament, personality and the environment (Strelau, 1998). The findings highlight that individual behaviour is not deterministic and can be influenced by the environment. This is also consistent with the literature (Oniszczenko et al., 2003). 
It was found that there are relationships between the neuroticism-anxiety and aggression-hostility subscales of temperament and resilience and character strengths. Lower levels of neuroticism-anxiety and aggression-hostility are associated in general with higher levels of resilience and character strengths. While these correlations are statistically significant, most of the correlation coefficients are not very large in magnitude. Furthermore, correlations between the impulsive sensation-seeking and sociability subscales do not exhibit statistically significant correlations with resilience and most character strengths. This implies that individuals who score high on the subscales of temperament are not precluded from developing their character strengths, and although the regressions indicate that resilience and character strengths may be predicted with reasonable accuracy, the correlations indicate, in line with the literature, that there is scope for the development of character strengths despite any potential biological predispositions.

\section{Temperament as a predictor of psychological well-being}

The second main objective of the study was to ascertain whether temperament traits can predict high and low levels of psychological well-being. As can be seen in the preceding discussion, there are many significant correlations among temperament, character strengths and resilience. However, in no previous studies have regression models been done in order to explore the relationships among temperament, character strengths and resilience. Similarly, no logistic regression models have been utilised to this end. There is also little research available from which to infer possible causal relationships among these constructs, and as such this aspect of the current study is a unique contribution.

Eight logistic regression models were fitted in order to assess to what extent temperament can predict high and low levels of character strengths and resilience.

Interestingly, the activity subscale of the Zuckerman-Kuhlman Personality Questionnaire (Zuckerman et al., 1993) featured as a predictor variable in all eight logistic regression models and was the most significant overall predictor of the VIA-IS (Peterson \& Seligman, 2004) in terms of the virtues of wisdom and knowledge, courage and humanity, as well as for the Resilience scale (Wagnild \& Young, 1993). Persons with high levels of activity therefore seem to have high levels of all virtues of character strengths, as well as higher levels of resilience as measured by the Resilience scale (Wagnild \& Young, 1993). Aggression-hostility featured as a significant predictor of all virtues other than that of courage and was the most significant overall predictor for the strengths of justice, temperance and transcendence. Aggression-hostility also featured as a significant predictor of resilience. Individuals with low levels of aggression and hostility therefore seem to exhibit high levels of all virtues of character strengths with the exception of courage. Also, individuals with low levels of aggression and hostility seem to exhibit high levels of resilience.

Importantly, these results indicate that there is indeed a biological element to psychological well-being, with an individual's temperament playing a large role in determining his or her character strengths as well as psychological resilience. The biological contributions to temperament, as indicated in the literature section, refer inter alia to the role of the autonomic nervous system, the central nervous system, hormones, neurotransmitters, hemispheric asymmetry and so forth (Daderman et al., 2001; Davidson et al., 2000; Gibson \& Cook, 1996; Tomarken et al., 1990; Wills et al., 2001; Zuckerman, 1991; Zuckerman et al., 1980). An understanding of which character strengths are most strongly associated with a particular temperament will guide interventions aimed at the development of those strengths. The implications of these results is that through an understanding of an individual's temperament, the resilience of that individual can to some extent be predicted, and specific interventions may be targeted at those who indicate low levels of resilience.

The literature indicates that psychopathology emerges when an individual crosses the threshold from 'normal' to 'abnormal' as a result of an accumulation of risk factors (DiLalla, 2004). The threshold model highlights the importance of genetic, environmental and developmental factors that interact and ultimately result in behaviours that have multiple determinants with upper and lower limits as a function of both genetic and environmental influences (DiLalla, 2004). The current study suggests that this may also be the case where psychological well-being is concerned. Further research into the development of a similar model for well-being is therefore warranted.

\section{Possible limitations of the study}

The results of the current study should be interpreted with caution as the sample was fairly homogeneous. Although the current study investigated temperament as a biologicallybased construct, other biological variables such as genetics and neurochemistry were beyond the scope of this research project. It should be noted that although, based on the current study's results, it is implied that character strengths and resilience are predicted by temperament, this link cannot be assumed to be causal and it cannot be ruled out that an additional third factor could have influenced the results. The VIA-IS (Peterson \& Seligman, 2004) can be criticised on a number of counts. It is possible that the VIA-IS could potentially suggest overly moralistic, religious or ethical views without presenting specifically psychological views (Grayling, 2004; Strümpfer, 2006). A further criticism of the VIA-IS is that the terms character and virtue are evaluative. Seligman (2002) concedes that science ought to be morally neutral and descriptive rather than prescriptive. However, he says that the objective of positive psychology is not to prescribe to individuals that they should be optimistic or spiritual per se but rather to describe the consequences of these traits, for example that high levels of optimism brings about less depression, improved physical health and higher levels of achievement. He further argues that what individuals choose to do with this information is dependent purely on personal goals and values.

\section{Suggestions for future research}

Future research aimed at identifying the specific nature of psychological well-being in various contexts could be valuable. Researchers should employ similar statistical techniques using the same variables with diverse samples in order to ascertain differences among individuals. Peterson and Seligman (2004) as well as Wissing and Van Eeden (2002) state that despite people's biological propensity to behave in a particular way, behaviour can be shaped and character strengths and resilience can thus be developed and enhanced. Future studies should investigate possible gender differences in temperament and well-being. Finally, researchers should investigate other biological concomitants of psychological well-being, such as genetics and neurochemical markers.

\section{Conclusions and implications}

Overall, it can be concluded that there are relationships among temperament, character strengths and resilience. The strengths perspective encapsulates 'assumptions and attributions about health, motivation, capacities, potential and social functioning' (Strümpfer, 2006, p. 12) and thus, in line with the positive psychology paradigm, it may be beneficial to teach young people strategies to develop and enhance character strengths and resilience as preventative measures for addressing psychological difficulties and mental illness. Intervention strategies that enhance psychological well-being (including character strengths and resilience) could be valuable in 
schools and tertiary education institutions, for example career guidance, psychological counselling, workshops, training courses, case studies, self-exploration activities, individual and group therapy, role modelling and mentoring, and community involvement projects.

It is possible that programmes aimed at enhancing wellness will begin to attract as much attention from parties interested in the healthcare professions as mental illness has done in the past. It is the task of psychologists to address psychological well-being as well as psychological illness in an integrated manner, in order to facilitate a preventative model aimed at enhancing health and wellness in individuals.

Frankl (1946, 1992, p. 104) states, 'between stimulus and response, there is a space. In that space is our power to choose our response. In our response lie our growth and our freedom.'

\section{REFERENCES}

Ahern, N.R., Kiehl, E.M., Sole, M.L., \& Byers, J. (2006). A review of instruments measuring resilience. Issues in Comprehensive Paediatric Nursing, 29, 103-125.

Allport, G.W., \& Vernon, P. (1930). The field of personality. Psychological Bulletin, 27, 677-730.

Aluja, A., Garcia, O., \& Garcia, L.F. (2002). A comparative study of Zuckerman's three structural models for personality through the NEO-PI-R, ZKPQ-III-R, EPQ-RS and Goldberg's 50-bipolar adjectives. Personality and Individual Differences, 33, 713-725.

American Psychiatric Association. (1994). Diagnostic and statistical manual of mental disorders. (4th edn.). Washington: American Psychiatric Association.

Anthony, E.J., \& Cohler, B.J. (Eds.). (1987). The invulnerable child. New York: Guildford.

Antonovsky, A. (1987). Unravelling the mystery of health: How people manage stress and stay well. San Francisco: Jossey-Bass.

Antonovsky, A. (1993). The structure and properties of the Sense of Coherence scale. Social Science and Medicine, 36, 725-733.

Bates, J.E., \& Wachs, T.D. (1994). Individual differences at the interface of biology and behavior. Washington: American Psychological Association.

Boddeker, I., \& Stemmler, G. (2000). Who responds how and when to anger? The assessment of actual anger response styles and their relation to personality. Cognition and Emotion, 14(6), 737-762.

Bohart, A.C., \& Greening, T. (2001). Humanistic psychology and positive psychology. American Psychologist, 56, 81-82.

Buss, A.H., \& Plomin, R. (1984). Temperament: Early developing personality traits. New Jersey: Lawrence Erlbaum.

Calicchia, J.A., \& Graham, L.B. (2006). Assessing the relationship between spirituality, life stressors, and social resources: Buffers of stress in graduate students. North American Journal of Psychology, 8(2), 307-320.

Carey, G. (2003). Human genetics for the social sciences. Thousand Oaks: Sage Publications.

Cloete, L. (2003). Die teoretiese en empiriese verwantskappe tussen besluitneming, temperament en samehangendheidsin [The theoretical and empirical relationships between decision making, temperament and coherence]. Unpublished master's thesis, Rand Afrikaans University (now University of Johannesburg), Johannesburg, South Africa.

Costa, P.T., \& McCrae, R.R. (2001). A theoretical context for adult temperament. In T.D. Wachs \& G.A. Kohnstamm (Eds.), Temperament in context (n.p.) New Jersey: Lawrence Erlbaum.

Daderman, A.M., Meurling, A.W., \& Hallman, J. (2001). Different personality patterns in non-socialized (juvenile delinquents) and socialized (air force pilot recruits) sensation seekers. European Journal of Personality, 15, 239-252.

Davidson, R.J., Jackson, D.C., \& Kalin N.H. (2000). Emotion, plasticity, context, and regulation: Perspectives from affective neuroscience. Psychological Bulletin, 126, 890-909.
Dawis, R.V. (1998). Scale construction. In A.E. Kazdin (Ed.), Methodological issues and strategies in clinical research (n.p.) (2nd edn.). Washington: American Psychological Association.

DiLalla, L.F. (Ed.). (2004). Behaviour genetics principles: Perspectives in development, personality and psychopathology. Washington: American Psychological Association.

Emmons, R.A., \& McCullough, M.E. (2003). Counting blessings versus burdens: An experimental investigation of gratitude and subjective well-being in daily life. Journal of Personality and Social Psychology, 84(2), 377-389.

Erikkson, M., \& Lindstrom, B. (2005). Validity of Antonovsky's Sense of Coherence scale: A systematic review. Journal of Epidemiology and Community Health, 59(6), 460-466.

Eysenck, H.J., \& Eysenck, M.W. (1985). Personality and individual differences. London: Plenum.

Frankl, V.E. (1946/1992). Man's search for meaning: An introduction to logotherapy. (4th edn.). Boston: Beacon Press. (Originally published in 1946 as Ein Psycholog erlebt das Konzentrationslager.)

Geyer, S. (1997). Some conceptual considerations on the sense of coherence. Social Science and Medicine, 44(12), 1771-1779.

Gibson, L.M., \& Cook, M.J. (1996). Neuroticism and sense of coherence. Psychological Reports, 79, 343-349.

Grayling, A. C. (2004). What is Good? The Search for the Best Way to Live. London: Phoenix.

Hart, K.E., Hittner, J.B., \& Paras, K.C. (1991). Sense of coherence, trait anxiety, and the perceived availability of social support. Journal of Research in Personality, 25, 137-145.

Keyes, C.L.M., \& Haidt, J. (Eds.). (2003). Flourishing: Positive psychology and the life well-lived. Washington: American Psychological Association.

Long, S.I. (2001). Occupational stress in men and women: A comparative study of coping resources. Unpublished master's thesis, Rand Afrikaans University (now University of Johannesburg), Johannesburg, South Africa.

Magnus, K., Diener, E., Fujita, F., \& Pavot, W. (1993). Extraversion and neuroticism as predictors of objective life events: A longitudinal analysis. Journal of Personality and Social Psychology, 65(5), 1046-1053.

Maslow, A.H. (1954). Motivation and personality. New York: Harper \& Row.

McCullough, M.E., \& Snyder, C.R. (2000). Classical source of human strength: Revisiting an old home and building a new one. Journal of Social and Clinical Psychology, 19, 1-10.

McLafferty, C.L., \& Kirylo, J.D. (2001). Prior positive psychologists proposed personality and spiritual growth. American Psychologist, 56, 84-85.

Murphy, L.B., \& Moriarty, A. (1976). Vulnerability, Coping and Growth: From infancy to adolescence. New Haven: Yale University Press.

Neuman, W.L. (2003). Social research methods: Qualitative and quantitative approaches. (5th edn.). Boston: Pearson Education, Inc.

Nicholson, I.A.M. (1998). Gordon Allport, character and the 'culture of personality': 1897-1937. History of Psychology, 1, 52-68.

Oniszczenko, W., Zawadzki, B., Strelau, J., Riemann, R., Amgleitner, A., \& Spinath, F.M. (2003). Genetic and environmental determinants of temperament: A comparative study based on Polish and German samples. European Journal of Personality, 17, 207-220.

Park, N., (2004). Character strengths and positive youth development. The ANNALS of the American Academy of Political and Social Science, 591, 40-54.

Peterson, C., \& Seligman, M.E.P. (2004). Character strengths and virtues: A handbook and classification. Oxford University Press, New York.

Ryff, C.D., \& Keyes, C.L. (1995). The structure of psychological well-being revisited. Journal of Personality and Social Psychology, 69(4), 719-727.

Santrock, J.W. (2003). Adolescence. (9th edn.). New York: McGrawHill. 
Seligman, M.E.P. (2002). Authentic happiness. New York: Free Press.

Seligman, M.E.P. (2003). Positive psychology: Fundamental assumptions. Psychologist, 16, 126-127.

Seligman, M.E.P., Steen, T.A., Park, N., \& Peterson, C. (2005). Positive psychology progress: Empirical validation of interventions. American Psychologist, 60, 410-421.

Slessareva, E., \& Muraven, M. (2004). Sensitivity to punishment and self-control: The mediating role of emotion. Personality and Individual Differences, 36, 307-319.

Snyder, C.R., \& Lopez, S.J. (Eds.). (2002). Handbook of positive psychology. Oxford: Oxford University Press.

Strelau, J. (1998). Temperament: A psychological perspective. New York: Plenum.

Strelau, J., Farley, F.H., \& Gale, A. (Eds.). (1986). The biological bases of personality and behaviour, Vol I. Washington: Hemisphere.

Strümpfer, D.J.W. (1990). Salutogenesis: A new paradigm. South African Journal of Psychology, 20(4), 265-276.

Strümpfer, D.J.W. (1995). The origins of health and strength: From 'salutogenesis' to 'fortigenesis'. South African Journal of Psychology, 25(2), 81-87.

Strümpfer, D.J.W. (2006). The strengths perspective: Fortigenesis in adult life. Social Indicators Research, 77, 11-36.

Tomarken, A.J., Davidson, R.J., \& Henriques, H.B. (1990). Resting brain frontal asymmetry predicts affective responses to films. Journal of Personality and Social Psychology, 59, 791-801.

Tusaie, K., \& Dyer, J. (2004). Resilience: A historical review of the construct. Holistic Nursing Practice, 18, 3-8.

Van Zyl, M. (2007). Temperament as biologiese basis vir salutogenese in adolessente [Temperament as a biological basis for salutogenesis in adolescents]. Unpublished doctoral dissertation, University of Johannesburg, Johannesburg, South Africa.
Vollrath, M. (2001). Personality and stress. Scandinavian Journal of Psychology, 42, 335-347.

Wagnild, G.M., \& Young, H.M. (1993). Development and psychometric evaluation of the Resilience Scale. Journal of Nursing Measurement, 1, 165-178.

Werner, E.E., \& Smith, R.S. (1982). Vulnerable but invisible: A study of resilient children. New York: McGraw-Hill.

Wills, T.A., Sandy, J.M., Yaeger, A., \& Shinar, O. (2001). Family risk factors and adolescent substance abuse: Moderation effects for temperament dimensions. Developmental Psychology, 37, 283-297.

Wissing, M.P., \& Van Eeden, C. (2002). Empirical clarification of the nature of psychological well-being. South African Journal of Psychology, 32, 32-44.

Zuckerman, M. (1991). Psychobiology of personality. New York: Cambridge.

Zuckerman, M. (2002). Zuckerman-Kuhlman Personality Questionnaire (ZKPQ): An alternative five-factor model. In B. De Raad, \& M Perugini (Eds.), Big five assessment (n.p.) Toronto: Hogrefe/Huber.

Zuckerman, M., Buchsbaum, M.S., \& Murphy, D. L. (1980). Sensation seeking and its biological correlates. Psychological Bulletin, 88(1), 187-214.

Zuckerman, M., Kuhlman, D.M., Teta, P., Joireman, J., \& Kraft, M. (1993). A comparison of three structural models of personality: The big three, the big five and the alternative five. Journal of Personality and Social Psychology, 65, 757-768. 